\title{
THE OULU WAY OF STRENGTHENING SOCIAL IMPACT OF SSH SCIENCES: FROM LINEAR MODELS OF IMPACT TO PRODUCTIVE INTERACTIONS AND BEYOND
}

JUHA TUUNAINEN, RAULI SVENTO , PENTTI HADDINGTON, KIRSI OJUTKANGAS AND SIRPA AALTO DOI: $10.22163 /$ fteval.2019.373

\section{INTRODUCTION}

$\mathrm{I}$ $n$ the recent years, the University of Oulu has taken an active role in supporting its research in social sciences and humanities (SSH). The support has manifested itself in the introduction of new structures such as the "Eudaimonia Institute"1, established in the early 2010s to promote and coordinate multi- and cross-disciplinary research in human sciences. "Eudaimonia" constitutes a community in which researchers are provided a collegial and supportive environment for carrying out research. It also serves as a platform in the new service concept called "Rapid Research Radicals" (3R), which aims to develop collaborative excellence and new openings in research. Connected to this, "Tellus Innovation Arena"2 offers methods and facilitation expertise to support various forms of collaboration. In addition to this, "Oulu Think Tank of Science and Society" ${ }^{3}$, which operates under the auspices of the "Eudaimonia Institute", was established to facilitate the interaction between scientists in SSH and the broader society. The "Oulu Think Tank" aims to produce policy-relevant research of internationally high standard, and to offer its expertise to different parties, such as companies and science policy makers. The SSH community has also been successfully included in the development of the university's strategy ${ }^{4}$ and profiling measures.

\section{BACKGROUND: SOCIAL IMPACT OF SCIENCE THROUGH PRODUCTIVE INTERACTIONS}

Academic research evaluation has seen important changes in the 2000s mainly related to changes in the societal role of university and the transformation of university governance towards increased social responsibility and accountability. The traditional research assessment was based on peer review and, subsequently, the number of scientific publications. In the 1990s, the demand for measuring economic returns from research funding increased and was closely associated with advancement of commercialisation of university research results. In the 2000s, various EU countries started to develop frameworks for analysing wider societal impacts of academic research, a task that was related to the introduction of the third mission of universities. Thus, the focus in the impact assessment shifted to the development of quantitative indicators through which the societal impact could be measured and used in allocating funds for research (Kearnes and Wienroth 2011).

Another development in impact assessment has been the shift from linear to interactive models of science's social impact. The fact that science has become "contextualised" and knowledge "socially robust" (Nowotny et al. 2001) has had implications for research policy with the end result of that being the replacement of linear processes of understanding the social impact with interactive approaches. Thus, instead of seeing science as the fountain of new knowledge, which would unproblematically flow from universities to society, interactive models, such as productive interactions (Spaapen and van Drooge 2011), acknowledge that societal actors other than scientists are increasingly important in creating science's societal impact. 
A common feature of the interactive approaches is their emphasis on situated and negotiated character of science within local social contexts (Haywood and Besley 2014) occupied by heterogeneous groups of stakeholders with specific interests of their own (Michael 2009). The question is thus no more about the unilinear transfer of knowledge to society, but about various ways in which societal actors are engaged in knowledge creation and application (Spaapen and van Drooge 2011). Interactive models therefore involve a more equal and collaborative communication between academics and societal actors, and increased levels of negotiation across the blurred border between science and society (Haywood and Besley 2014). By so doing, they also help us to appreciate how societal stakeholders attribute value to scientific findings and make use of these as a part of their own activities.

Among the most popular interactive concepts of science's social impact is that of productive interactions. The concept was designed to circumvent the problems of attribution, temporality and causality in impact assessment by looking at interactive processes by means of which impacts are created in practice by heterogeneous sets of social actors. The concept seeks thus to address the iterative production of new understanding and mutual learning at the interface of science and society. According to Spaapen and van Drooge (2011: 212), productive interactions can be defined as "exchanges between researchers and stakeholders in which knowledge is produced and valued that is both scientifically robust and socially relevant". In addition, Spaapen and van Drooge (2011: 212) elaborated that the interaction is productive if "it leads to efforts by stakeholders to somehow use or apply research results". Productive interactions are thus preconditions of achieving societal impacts of science or "intermediate indications of de facto social impact" (Spaapen and van Drooge 2011: 216).

In our view, productive interactions are among the most fruitful suggestions for understanding the social impact of science but have limited value in providing differentiated understanding about the various modes of interaction that take place during such mutual involvement. What is needed is a more tangible framework with the help of which one could differentiate between various kinds of productive interactions and articulate the role new scientific understanding has in solving societal problems. For such a framework, we will use a distinction made between three dimensions of societal impact of science, 1) epistemological, 2) artefactual and 3) interactional-institutional foundations of impact (Miettinen et al. 2015). Further, we will illustrate how such an approach could be used to analyse energy research led by scholars working in Oulu Business School, the University of Oulu, Finland. We do so to stimulate self-reflection of research communities and to help them articulate the societal impact of their research whenever it is needed.

\section{BRIGHT CLOUDS - DARK CLOUDS (BCDC) ENERGY CONSORTIUM AS A CASE EXAMPLE}

The research consortium we analyse, "BCDC Energy", was funded by the newly established Strategic Research Council of Finland (SRC), which is set to encourage and enable the discourse between scientific research and society. The major innovation political rationale to precede the creation of SRC was the recognition of how societal decision-making was lacking research-based evidence. To fill this gap, SRC funds highquality research with actual societal impact with an annual budget of around 55 million euros. It encourages researchers to find concrete solutions to so-called grand challenges. Solving grand challenges requires multidisciplinary approaches and active interaction among a very heterogeneous set of societal actors. Thus, an important element of SRC projects is active interaction between those who produce new knowledge and those who use and further elaborate it.

"BCDC Energy", the case example we chose to analyse in this paper, is a large, multidisciplinary and multiorganisational consortium chosen in the first call of the SRC research funds in 2015. The consortium is led by Oulu Business School, the University of Oulu, and the other partners are: the Centre for Wireless Communications and Department of Information and Communication Studies at the University of Oulu, the Finnish Environment Institute (SYKE), the VATT Institute for Economic Research, the Department of Computer Science at University of Helsinki and the Finnish Meteorological Institute (FMI). The aim of the consortium is to develop new types of services to integrate renewable resources into the smart grids in cost efficient ways.

\section{EPISTEMOLOGICAL DIMENSIONS OF ACHIEVING IMPACT IN "BCDC ENERGY"}

The epistemological dimension of productive interactions addresses what new research results and understanding of relevant phenomena have contributed to the solving of technological and societal problems. The basic research question of "BCDC Energy" relates to the intermittency problem created to the energy system through increasing share of renewable energy sources. Wind and solar energy production cannot be dispatched in similar ways than traditional power technologies. This creates new types of uncertainties into the system. "BCDC Energy" search solutions from different types of flexibilities both in supply side and demand side of the system. In supply side, the role of hydro power in compensating intermittency generated by renewables has been studied. It has been shown how hydro power has positive potential in hydro dominated markets like the Nordic electricity market "NordPool" (Huuki et al. 2017). From the demand side, consumer flexibility has been studied by analysing the role of real time pricing (Huuki et al. 2017). It has been shown that real time pricing can play a role in solving the intermittency problem but there are also constraints related to its efficiency (Kuhnlenz et al. 2018). Consumer attitudes have been analysed through large surveys using the choice experiment method. It turns out that consumers are willing to adapt new technologies and contracts if they get acceptable compensations from the disutility that are created to them (Ruokamo et al. 2018, Krishnamurty et al. 2018).

The research community of "BCDC Energy" quite early recognised that without multidisciplinary knowledge the project could easily have focused into narrowly defined dimensional features of the ongoing energy market disruption. Furthermore, the project's understanding of the need to take all market contexts into consideration became obvious in the workshops organised. The project is thus confident that the broadening of its view and research agenda has helped the researchers to communicate their scientific findings with and serve the needs of the energy market stakeholders. "The Finnish Transmission System Operator" (TSO) Fingrid published a working paper and a related report entitled "Electricity market needs fixing - What can we do?" in May 2016. Together with 
the other energy-related SRC consortia, i.e., "Smart Energy Transition" (SET) and "Transition to a resource efficient and climate neutral electricity system" (El-Tran), "BCDC Energy" delivered a joint comment to this initiative. A round-table discussion based on the arguments put forward in that comment was then organised by Fingrid. In addition to this, the energy-related SRC projects published a policy brief emphasising the need to move into coal neutral society ${ }^{5}$ ().

Finally, based on the multidisciplinary research by the BCDC consortium, a novel terminology "Clean Energy Research" was compiled to the Bank of Finnish Terminology in Arts and Sciences hosted by the University of Helsinki (www.tieteentermipankki.fi). In this way, the results of the project can be utilised by wider audiences also after the end of the project. The fact that "The Institute for the Languages of Finland" picked "energiasääennuste" (energy weather forecast) as a new word in their Finnish words database indicates that the project has achieved a significant epistemic outcome and a new concept related to the disruption of the energy markets in Finland. The new term and the related software application (see artefactual dimension below) keep spreading - without any effort from the consortium - to a variety of internet sites (e.g., http:// www.finsolar.net/aurinkoenergia/aurinkoatlas/).

\section{ARTEFACTUAL DIMENSIONS OF ACHIEVING IMPACT IN "BCDC ENERGY”}

A key ingredient in solving the intermittency problem is development of energy related forecasts. This is why meteorologists were included in the consortium from the beginning. Already in the consortium kick-off meeting in January 2016 this proved to be a good choice. During the meeting dinner, business collaborators discussed with meteorologists and economists on how to make energy related weather forecasts more practical. During the discussions an idea of an application showing the forecast of wind and sunshine in energy units popped up. This sounded like a good idea and the development started immediately. In June 2016 the application "Energy Weather Forecast" ${ }^{\text {" }}$ (http://www.bcdcenergia.fi/ en/energy-weather/) was opened in the consortium web page. It is an open access application showing 24 hours hourly forecasts for wind and solar power in $\mathrm{kWh}$. It shows these forecasts for all 200 measurement points of the Finnish Meteorological Institute in Finland. It is scaled for $2.5 \mathrm{~kW}$ solar panels and similar size wind mills so that they are applicable even in detached single household houses. The forecast is updated every hour. The application turned out to be very popular. From its opening it has reached over 12.000 visits. The development process of the Energy Weather Forecast has also been documented (Suorsa et al. 2018).

\section{INTERACTIONAL-INSTITUTIONAL DIMENSIONS OF ACHIEVING IMPACT IN BCDC ENERGY}

The interactional-institutional dimension of productive interactions includes forms and forums of collaboration between scientists and other societal actors. In the BCDC consortium, the involved researchers work in the interface between science and energy markets. Therefore, the companies familiar with the market situation in the energy sector are vital partners in developing the service platform the project aims to build. Consequently, the project's Advisory Board (AB), which involves important societal stakeholders, was formed at the beginning of research. The aim was to use co-creation methods to develop the services with the key players of the energy markets, and to share knowledge of the recent research with them. Interactive events and workshops organised by "BCDC Energy" with the AB have been the means to develop models for new types of service platforms. These means allow multidisciplinary, multi-organisational and multi-professional collaboration. Face-to-face interactions in the workshops enable finding alternative solutions to chicken-and-egg problems typical to two-sided platforms. In addition, the members of the $A B$ have their own online forum, which has been used to share, store, produce and manage information related to the project.

External interaction and communication in BCDC is designed and implemented in collaboration with the communications' units of the partner universities, other organisations and partners involved in the work of the $\mathrm{BCDC}$ consortium. The project has managed to utilise the resources lying in the multiorganisational structure of the consortium and developed a fruitful, reciprocal collaboration network with the communication units involved. With the communication specialists of different disciplines, a stronger and wider competence has been in the BCDC community's reach. This interaction network supports managing interdisciplinary and transepistemic issues. The perceptions of the researchers and communication professionals on projects' science communication are also being investigated in a separate work package.

The "BCDC Energy" communication network functions as a meeting point for highly esteemed professionals and colleagues. Face-to-face meetings with a timely agenda and informal in nature, have been held since the beginning of the project with project partners and the "Kaskas Media agency". The communication units design and develop a variety of methods for science communication and the communication specialists provide support and empower the researchers to communicate their research in public and online. This support includes editorial help, repeatedly checked routines and informal discussions regarding communication. In order to open up scientific work and processes of creating new knowledge the BCDC project publishes a blog and tweets. Monthly at least one expert blog is published on the "BCDC Energy" website and shared via the project's communication network. The participation and representation of the "BCDC Energy" consortium in social media is secured via weekly appearances in Twitter, where the researchers also actively follow other peers and stakeholders. The principal investigator of the "BCDC Energy" consortium leads by example and regularly publishes updates of the research progress as BCDC story posts on the BCDC website. 
WHAT CAN THE UNIVERSITY LEARN? CAPITALISING SUCCESS AND INSTITUTIONALISING GOOD PRACTICES IN THE FUTURE

The interactive models of science's social impact, together with the new organisational structures ("Eudaimonia Institute"; "Oulu Think Tank" of Science and Society; "GenZ Hub") provide a solid background to develop, spread and institutionalise the identified good practices for strengthening the societal outreach of SSH research at the University of Oulu. First, the good practices identified in the BCDC project - and other projects - will be spread to the SSH community in Oulu. Second, "Eudaimonia" and "Oulu Think Tank" will collaborate with other focus institutes at the university to introduce SSH research on a regular basis in various events. Third, the identified good practices will be used to establish and strengthen connections to the broader society to promote and add to impact of SSH research. Finally, as a brand new endeavour, they will facilitate the activities of the new profiling effort of the university, "Genzproject", starting in August 20187.

"GenZ" - Generation Z and beyond: Co-evolution of human capabilities and intelligent technologies in the 21 st century - is a cross-disci- plinary project led by SSH-sciences. It explores how human skills and capabilities can be strengthened in the rapidly transforming world that is increasingly driven by new digital and technological solutions. Further it involves ambitious aims to initiate co-creation activities in five faculties within the university, and to facilitate societal outreach and impact (see Figure 1). More specifically, concrete activities to support societal impact of SSH sciences include:

- utilising the university's new research organisation, profiling projects and service structure also for knowledge transfer and societal impact (e.g. as of 2017 each faculty has their own dedicated communication specialist who helps design and implement interaction plans to and with stakeholders);

- reflective and co-creative communicative practices within multiand cross-disciplinary research communities;

- new interactive practices for research groups and communities to make social impact: blogs, encouraging active participation in the social media, and research story posts;

- regular (e.g. annual) graduate school courses, seminars and workshops facilitated by "Eudaimonia", "Oulu Think Tank" and the "GenZ Hub" that provide platforms and forums for SSH scientists and stakeholders to reflect on their practices, identify common interests, share knowledge, and establish possible collaboration across disciplines and interest groups.

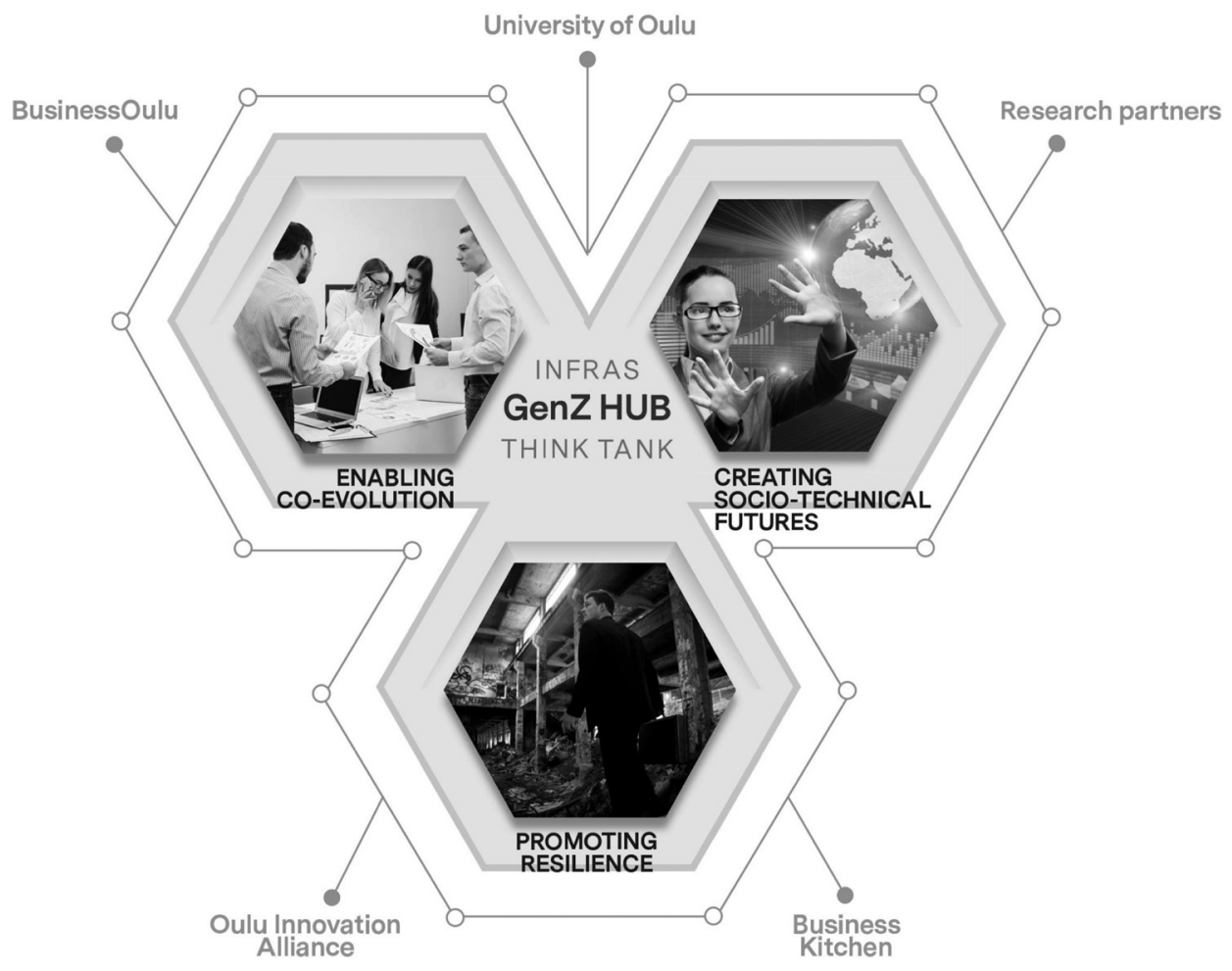

Figure 1: The Oulu way - Facilitating cross-disciplinary research in SSH sciences; responding to a global challenge; strengthening societal outreach and impact. 


\section{REFERENCES}

Haywood, B. K. and Besley, J. C. (2014). Education, outreach, and inclusive engagement: Towards integrated indicators of successful program outcomes in participatory science. Public Understanding of Science 23/1, 92-106.

Huuki, H., Karhinen, S., Kopsakangas-Savolainen, M. and Svento, R. (2017). Flexible Demand and Flexible Supply As Enablers of Variable Energy Integration. https://papers.ssrn.com/abstract=2966053

Kearnes, M. and Wienroth, M. (2011). Tools of the trade: UK research intermediaries and the politics of impacts. Minerva 49: 153-174.

Krishnamurthy, C. K. B., Vesterberg, M., Böök, H., Lindfors, A. V. and Svento, R. (2018). Real-Time Pricing Revisited: Demand Flexibility in the Presence of Micro-Generation. Energy Policy 123, 642-658.

Kuhnlenz, F., Nardelli, P.H.J., Karhinen, S. and Svento, R. (2018). Implementing flexible demand: Real-time price vs. market integration. Energy, 149, 550-565.

Michael, Mi. (2009). Publics Performing Publics: of PiGs, PiPs and Politics. Public Understanding of Science 18/5: 617-630.

Miettinen, R., Tuunainen, J. and Esko. T. (2015). Epistemological, Artefactual and Interactional-Institutional Foundations of Social Impact of Academic Research. Minerva - A Review of Science, Learning and Policy 53/3, 257-277

Ruokamo, E., Kopsakangas-Savolainen, M., Meriläinen, T. and Svento, R. (2018). Towards flexible energy demand - preferences for dynamic contracts, services and emission reductions. Paper presented at the $6^{\text {th }}$ World Congress of Environmental Economics, Gothenburg, June 2018.

Spaapen, J. and van Drooge, L. (2011). Introducing 'productive interactions' in social impact assessment. Research Evaluation 20/3: 211-218.

Suorsa, A., Svento, R., Lindfors, A. and Huotari, M.-L. (2018). Knowledge creation and interaction in an RandD project: the case of the Energy Weather Forecast, Mimeo.

\section{AUTHORS}

\section{JUHA TUUNAINEN}

Oulu Business School, University of Oulu

Pentti Kaiteran katu 1, Oulu, 90570 (Finland)

E: juha.tuunainen@oulu.fi

\section{RAULI SVENTO}

Oulu Business School, University of Oulu

Pentti Kaiteran katu 1, Oulu, 90570 (Finland)

E: rauli.svento@oulu.fi

\section{PENTTI HADDINGTON}

Faculty of Humanities, University of Oulu Pentti Kaiteran katu 1, Oulu, 90570 (Finland)

E: pentti.haddington@oulu.fi

\section{KIRSI OJUTKANGAS}

Research Support Services, University of Oulu Pentti Kaiteran katu 1, Oulu, 90570(Finland)

E: kirsi.ojutkangas@oulu.fi

\section{SIRPA AALTO}

Faculty of Humanities, University of Oulu Pentti Kaiteran katu 1, Oulu, 90570 (Finland)

E: Isirpa.aalto@oulu.fi 